\title{
Kopftuch(verbot) in der Arztpraxis?
}

Gwendolyn Gemke • Felix Schiffner, München

Kleiderordnung in der Praxis? Inwieweit kann der Praxisinhaber auf die Arbeitsbekleidung seiner Mitarbeiter Einfluss nehmen? Gerade Arztpraxen mit Schwerpunkt in der ästhetischen Medizin legen Wert auf ein einheitliches, modernes Äußeres ihrer Mitarbeiter. Dies soll die innere Ausrichtung der Praxis auch nach außen widerspiegeln.

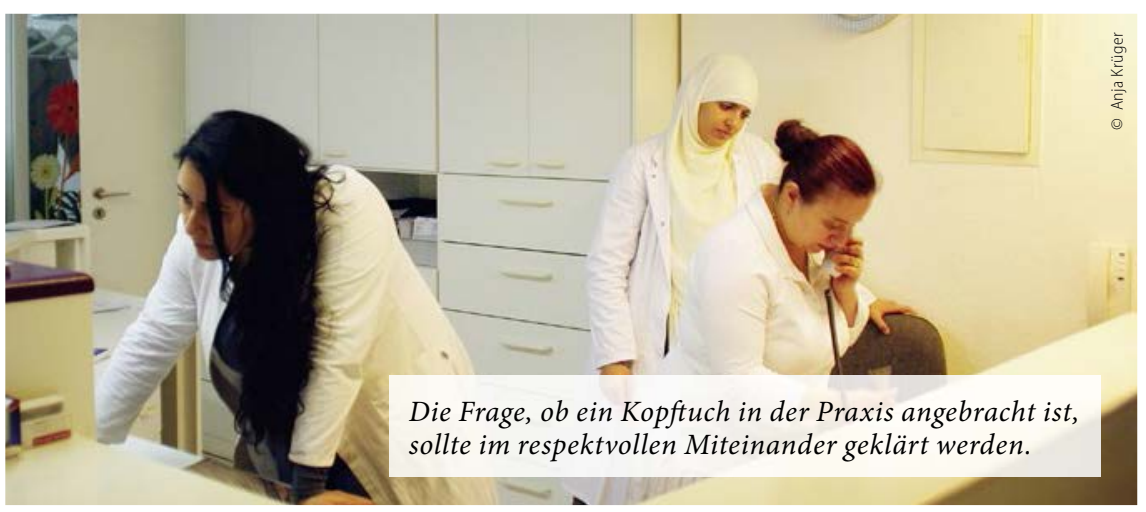

Der Wunsch einer muslimischen Mitarbeiterin, als Ausdruck ihres Glaubens ein Kopftuch, also sogenannte Glaubensbekleidung zu tragen, kann hier auf Unverständnis stoßen und nicht immer gelingt es, den Konflikt einvernehmlich zu lösen. Während manche Arbeitgeber diesen Wunsch problemlos akzeptieren, stellt er für andere eine echte Herausforderung dar. Interessant wird dann die rechtliche Frage, ob der Arbeitgeber entsprechende Vorgaben machen und ein Kopftuchverbot oder Verbot sonstiger Glaubensbekleidung für seine Praxis aussprechen darf.

Im Grundsatz steht es dem Arbeitgeber im Rahmen seines Direktionsrechts zu, seinen Mitarbeitern Vorgaben für die Berufsbekleidung zu machen. In der ärztlichen Praxis wird den Mitarbeitern regelmäßig aufgegeben, einheitlich gestaltete Berufsbekleidung zu tragen. Wichtig ist dabei ein ästhetisches und hygienisches Erscheinungsbild.

An seine Grenzen stößt diese Direktions- und Weisungsbefugnis, wenn eine Mitarbeiterin Glaubensbekleidung trägt. Das Tragen religiöser Symbole, worunter z.B. auch das Kopftuch fällt, genießt durch die in der Verfassung garantierte Religionsfreiheit sehr hohen Schutz. Die- ser Schutz greift auch im Rahmen der Berufsausübung, was dazu führt, dass zwei Grundrechte aufeinanderprallen: Einerseits die Religionsfreiheit der Mitarbeiterin gemäß Art. 4 Grundgesetz (GG), anderseits die Unternehmerfreiheit des Arbeitsgebers gemäß Art. 12 GG. Diese Kollision ist nach der Rechtsprechung durch eine intensive Abwägung zu lösen, an deren Ende einem der beiden Grundrechte der Vorrang gewährt wird.

Bereits 2002 hatte sich das Bundesarbeitsgericht (BAG, Urteil vom 10.10.2002, Az. 2 AZR 472/01) mit einem Fall zu befassen, in dem einer Kaufhauskassiererin das Tragen eines Kopftuchs verboten wurde. Das BAG entschied zu Gunsten der Kassiererin, der Arbeitgeber musste das Tragen des Kopftuchs dulden. Nach sorgfältiger Abwägung der Grundrechte kam das BAG zu dem Ergebnis, dass der Religionsfreiheit der Vorrang gebühre, und zwar auch dann, wenn die Arbeitnehmerin in einem publikumswirksamen Arbeitsbereich - wie vorliegend an der Kasse - tätig sei. Daran änderte auch eine interne Kleiderordnung des Kaufhauses nichts, die vorschrieb, sich „dezent und zurückhaltend zu kleiden“.
Ist dies auf eine Arztpraxis übertragbar? Nimmt man die Grundsätze des Bundesarbeitsgerichts und des Bundesverfassungsgerichts ernst, dann ja. Das heißt, der Arzthelferin kann vom Arbeitgeber das Tragen eines Kopftuches nicht verboten werden, und zwar auch dann nicht, wenn der Praxisinhaber eine konkrete Vorstellung bezüglich des äußeren Erscheinungsbilds seiner Mitarbeiter hat. Eine andere Entscheidung wäre lediglich dann denkbar, wenn der Arbeitgeber beweisen kann, dass gerade wegen der getragenen Glaubensbekleidung erhebliche Umsatzeinbrüche zu verbuchen sind oder Patienten ausbleiben. Dieser Beweis ist in der Praxis jedoch kaum zu führen.

Anders würde der Fall auch dann beurteilt, wenn erhebliche Gründe der Hygiene oder aber der Arbeitssicherheit das Tragen der Glaubensbekleidung verbieten. Denkbar wäre ein Turbanverbot bei herrschender Helmpflicht auf einer Baustelle, auch bei einer Burka in der Arztpraxis könnte man Hygienebedenken anbringen. Ansonsten sind derartige Sicherheitsbedenken jedoch eher selten zu begründen.

Obwohl das BAG bereits 2002 für das islamische Kopftuch eine klare Entscheidung zu Gunsten der Religionsfreiheit getroffen hat, ist die Rechtslage für andere Glaubensbekleidungen noch gänzlich ungeklärt. Das Thema erfordert im Praxisalltag viel Fingerspitzengefühl. Und es lohnt, die rechtlichen Entwicklungen und Vorgaben im Auge zu behalten und sich vor Erteilung einer Mitarbeiterweisung oder Aussprache einer Kündigung Rechtsrat einzuholen.

Sozietät Hartmannsgruber Gemke

Argyrakis \& Partner Rechtsanwälte

\author{
Rechtsanwälte und Fachanwälte für \\ Medizinrecht \\ Dr. Gwendolyn Gemke, Felix Schiffner \\ August-Exter-Straße 4, 81245 München \\ www.med-recht.de
}

